\title{
Study and Analysis of Obstacles and Challenges Facing Ship-Repair Industry in Iran
}

\author{
Reza Bozorgpour*, Behrouz Omaraee, Mohsen Vaez Zadeh Asadi \\ Maritime Transport Department, Khark Branch, Islamic Azad University, Khark, Iran \\ Email: ^bozorgpourr@gmail.com, b.omaraee@gmail.com, mv_asadi90@yahoo.com
}

How to cite this paper: Bozorgpour, R., Omaraee, B. and Asadi, M.V.Z. (2017) Study and Analysis of Obstacles and Challenges Facing Ship-Repair Industry in Iran. Open Journal of Marine Science, 7, 485-493.

https://doi.org/10.4236/ojms.2017.74034

Received: March 12, 2017

Accepted: October 7, 2017

Published: October 10, 2017

Copyright $\odot 2017$ by authors and Scientific Research Publishing Inc. This work is licensed under the Creative Commons Attribution International License (CC BY 4.0).

http://creativecommons.org/licenses/by/4.0/

\begin{abstract}
Nowadays, shipping industry which is the backbone of economic development has affiliated to ship maintenance and repair industry. This industry provides technical maintenance services to ships in a way to enable them to meet the requirements and regulations of the International Maritime Organization and maintaining the vessels at high technical standard \& continual seaworthiness condition. Maintaining the minimum requirement of classification societies on the ships is solely taken place with repairs. The research method is an applied study in sake of aim and a descriptive study in sake of nature. This research has been conducted to examine causes and factors contributed to failures repairing in dry docks in the country; using the obtained results, an approach has been presented to reduce obstacles existing in country and reach to standard international levels. The problems include lack of suitable strategy, lack of government support, governmental facet of the structure of this sector, cumbersome laws, customs problems, lack of specialized workshops, low levels of technology and lack of new technology etc. Thus, by taking amendment to the cumbersome rules, taking advantage of industry and modern technology experts, increasing productivity and competitiveness, centralizing active domestic and foreign workshops at private sector, facilitating timely supply of parts and accessories, using research and development sector, increasing quality, reducing costs and repair time, selecting secure industrial-trade partner and etc. can pave the way in this context.
\end{abstract}

\section{Keywords}

Maritime Transport, Ship Repair Dry Dock, Periodic Maintenance, Travel Repairs, The Persian Gulf, The Ship

\section{Introduction}

Ship Repair Strategic Industry in Iranian dry docks has started since 1970 almost 
simultaneously with its competitors such as united Emirates, South Korea and Bahrain [1]. While each of them has allocated a contribution of the global repairs to themselves, our country has not reached to a significant success in this industry. Thus, it is asked that the factors have caused failure in ship repair industry in country especially for high capacity ocean going vessels. The researcher seeks a solution to problem so as to help to develop the solutions and suggestions by studying the status of domestic and foreign dry docks at this industry, competitors' success standards and getting the practitioners', experts' and researchers' views and analyzing the obtained information [2]. Whether it can reach to solution with study on the relationship between dependent and independent variables, such as capital, skilled manpower, competent manager and tactician, modern technologies, companies and partners to bring this industry, culture of people, directors and employees of the Company, terms of geography and climate, trade and national laws, Customs law, business communication and relations with other countries, attracting foreign capital, guarantee capital and ensuring internal and external partners, adherence to commitments, government support, advertising, Cruel sanctions, managers' participation in corporate profits, increase productivity and reduce costs and improve quality, national commitment, alignment and cooperation between manufacturers and service providers with the customer, domestic and foreign competition, low profit lending to companies as well as to buyers and clients ship repairs, tax breaks and subsidies to Shipbuilding and ship repair customers [3].

\section{Effective Measures in the Progress of Ship Repair in Iran}

Since relatively effective steps by the Integrated Shipbuilding and Offshore Industries (ISOICO) have been taken in this area, it is expected to witness progress in the ship repair in the years ahead by continued policies. In this regards, 44 vessels have been repaired in the complex and as a result of the local form of these repairs, a $30 \%$ reduction has brought in costs for the country. Trade comes to realize when the products reach to the consumer and this becomes possible by means of transport industry. Given that the maritime transport industry due to its unique advantages in the world of today has been allocated with about 90 percent of the volume of imported and exported goods [4]. Therefore, having a safe and efficient fleet of marine in accordance with international and environmental standards and the ability to compete on the global stage is essential. This is not possible unless making the periodic maintenance on ships under operating service which require maintenance infrastructure. Ship repair industry in the world is the most influential factor that influences the maritime transport directly [5].

Ship owners require ship repair and maintenance to comply with international requirements and standards, maintain safety and keep the vessels under operation. Timely repairs warranties proper performance of engine, machines and all the equipment on ships and lead to increase in lifespan of ships in addition to reduction in fuel consumption and environment protection. Although this 
necessity and need has been felt for many years ago, but domestic ship repairs have failed to meet customers' expectations. An attempt is made to contribute the researcher's studies to compensate weaknesses in this strategic industry [6].

\section{Literature Review}

Boris Butman, 2014 conducted a study entitled "Fundamentals of ship maintenance and repair for future marine engineers" intended to emphasize the importance of teaching the subjects related to ship engineering operations and specifically ship maintenance and repair, to analyze the existing practices in IAMU member institutions and to offer practical recommendations. Although the share of maintenance and repair in the cost of ship operation is substantially lower then, fuel and crew expenses and its impact are substantial. Besides the direct costs, this impact includes related down time that reduces revenues, delays causing lost opportunity and more revenue loss, inefficient quality of repairs, affecting ship performance and causing emergency repairs and down time. The fundamentals of ship maintenance and repair are examined from perspective of theoretical and practical knowledge. The importance and expected outcomes of teaching the subject is discussed as a way of enhancing the knowledge and providing a needed edge in landing a better sailing job and also a possible future job ashore [7].

Barania et al. (2012) in a research entitled "study on effect of human resources training management on shipbuilding industry and maritime industry development" concluded that by training associated human resources and using modern technology and shipbuilding management software in shipbuilding industry instead of previous shipbuilding methods in our country, the required time to build a container ship was reduced to three years, yet this reduces to 20 months by solving the existing management problems in this context which are mentioned as follows. Large floating projects which are implementing under management by maritime industry organizations by experts and technicians in line with Iran's self-sufficiency represent a sample of proper use of technology instead of traditional methods of the past. It is discussed that by proper implementation of this technology and proper management, it can launch production lines of different vessels in our country and thus the next generation of ships can become more efficient and in general all the requirements and standards related to health and comfort of employees on vessels are predicted and the required time and production cost of vessels will reduce to a large extent. Farhoumand (2012) in an article entitled study on ship repair and maintenance industry and determination of the market share in Iran(case study: ISOICO) concluded that they can examine the causes to weakness at ship repair and maintenance industry by studying performance of maritime industry in country and present the fundamental causes to weakness at this industry as follows [8]:

- Non-compliance with Investment priorities;

- Existing improper planning in maritime system of country;

- Inattention to above qualitative factors and provided services and low 
manpower productivity;

- Lack of use of abilities and facilities at private sector by companies in ship repair industry;

- Lack of companies and workshops providing service, spare parts and tools;

- Inattention to research and development sector and lack of relationship with scientific centers of country;

- Weakness at marketing affairs;

- Weakness at formulation of suitable strategy;

- Failure in attracting shipping companies' trust;

- Currency red tape rules.

\section{Types of Ship Repair}

In most sources, ship maintenance and repairs have been classified to two parts of periodic and travel maintenance, but classification of this industry to $5 \mathrm{sec}$ tions below seems more logical on the basis of direct and indirect experience of nearly three decades of researcher.

1) Daily maintenance and during operation of the ship: Repairs which are made by ship technical staff based on tasks and in accordance with manufacturer's instructions in routine like way, or they are made based on the need and urgency arisen during the trip and during ship operation without the need for external repairman and on the basis of their technical capabilities.

2) Travel Repair: it is called to a series of routine or emergency ship repairs which is beyond the capacity of ships staff as far as time and required facilities is concerns. Thus, as needed, the ship will be dispatched to selected Repair shop short-term for various predicted repairs.

3) Periodic repairs: Ships under 15 lifespans once per 5 years and above 15 years once per two and half years exert their operating transport cycle and refer to repair dry dock to make overhaul in ship body, lower surface of water surface, equipment and machineries at powerhouse to deck and navigation of ship to repair dry dock, called with periodic repair.

4) Repairs related to the ship use conversion and change: this refers to all the services related to change in structure and configuration of ships in a way to enable them to use various operating goals with initial goals of shipbuilding [9].

5) Unpredicted repairs without advance planning: any required repair which emerges as a result of the factors such as events, accidents and so on and leads to failure of any of the appliances and equipment such as shafts and propellers, engines/major and minor engines, damage to equipment and fortifications of ship. In this case, it requires making repairs as soon as possible to return the ship to the healthy state and classifying it qualified by maritime capability [10].

\section{Research Method}

The present research is an applied and descriptive survey, aimed to test theories and discover the principles governing the relationships between phenomena. 


\section{Statistical Population}

To take accuracy in results of research, statistical population of this research has been selected among NITC employees, IRISL and Ship Repair dry docks and experts in this industry, and the questionnaires have been distributed and collected among a certain number of them.

\section{Sample Group and Sampling Method}

Sample size (120) consists of specialized employees at National oil companies, IRISL and shipbuilding and ship repair. Since sample size has been estimated with 96 persons, 120 questionnaires have been distributed among them to be more insured and the researcher succeeded to collect 86 filled questionnaires. The obtained data from these 86 questionnaires became the basis to conduct this research. It should be noted that one of the collected questionnaires lacked sufficient validity.

\section{Data Collection Method}

In the present research, the required data were collected via the questionnaires consisting of 5 questions on biography and 28 tests and distributed among 120 persons. In this research, the questionnaire has been used to collect data and information has been collected via publications, library sources, the Internet and scientific sites and interview. Questionnaire refers to a scientific tool to measure and collect a specific type of data in a way that the questionnaire is considered at the first step at investigation step, if the research steps are divided into three steps of investigation, explanation and interpretation. If the research steps are classified in seven steps below: problem statement, hypotheses formulation, data collection, classification of obtained information, study on information and detection of cause and effect relationships, determination of validity of hypotheses and preparation of research report, the questionnaire is considered at the third step, data collection. With these explanations, it is specified that questionnaire refers to one of the most common techniques for data collection particularly in survey. Software SPSS-version 21 is used to analyze data.

\section{Study on Validity and Reliability of Measurement Instruments}

Before using measurement instruments, researcher requires ensuring about validity of measurement instruments as well as their reliability.

\section{Validity}

Before ensuring about measurement instruments and using them at the major step of data collection, it requires ensuring about validity of considered instruments. Validity implies that the instrument measures the considered features rather than another variable. To measure validity of measurement instruments, content validity has been used. For this, the preliminary questionnaire was given 
to the experts and professors specialized at this field and then validity of questionnaire was confirmed after making the considered modifications.

\section{Reliability}

To determine reliability of questionnaire to ensure about homogenous results under the same conditions, Cronbach's alpha method has been used. This method is used to calculate internal consistency of the measurement instruments including questionnaire. To calculate Cronbach's alpha coefficient, firstly variance on scores of each subset of questions in the questionnaire and total variance have to be calculated and then Cronbach's alpha value has to be determined using formula below:

$$
r=\frac{j}{j-1}\left(1-\frac{s_{j}^{2}}{s^{2}}\right)
$$

where $J, s_{j}^{2}, S^{2}$ represent number of sub-sets of questions in the questionnaire, variance of $f^{\text {th }}$ subset and total variance of test. The obtained coefficient for the questionnaire equaled to 0.88 using software SPSS which is an acceptable coefficient.

\section{Discussion and Conclusion}

Since domestic ship owners tends to send their ships abroad for repair, which is pinpointed by some people. However, if we think free from emotions and logically, certainly we accept that the revenue and profitability of the shipping industry achieved through trade in international markets is merely obtained by moving cargo fleet. Operation of the ship, having the necessary conditions to estimate the requirements and regulations of the International Maritime Organization, the terms and conditions under the flag, having favorable conditions and maintaining the required minimum standards of classification organizations are obtained by timely and favorable repairs. Any withdrawal from operational service and ship daily delay are detrimental to business. The problems include customs problems, red tape regulations and rules, currency difficulties and fluctuations, governmental organizations, lack of presence of private sector and representatives of manufacturing companies of parts, equipment and foreign modern machinery in the country, lack of speed in providing parts and supplies, labor laws and etc. Thus, until these problems are not solved, it cannot expect favorable development at ship repair sector. What factors cause failure at ship repair industry in Iran. With regard to the research findings, unsuitable investments in this industry in terms of optimal use of domestic investment, failure in foreign industrial investments, lack of attracting shippers' trust in terms of long repair time and high repair cost, low quality of work, lack of possibility to access to equipment, technical parts and specialized experts, cumbers home rules and abundant customs and currency problems, lack of certain strategy, low technology level and manpower productivity and negative effect of cruel international 
sanctions are the factors affecting failure in repair of this industry. Whther it can reach to a suitable position by revision on ship repair industry? Under government's determination to develop a clear strategy in the form of a short-term medium and long term scheduling to remove troublesome rules, elimination of tariff and trade barriers in import and export, legal and regulatory requirements in relevant government agencies, discounts or eliminating taxes, identified subsidies until a certain time, the way is paved to take next steps mentioned in question below. Under maximum proposed approaches, it can convert the poor ship repair centers at country to the center of repair industry in the strategic region of Persian gulf and reach the country to a considerable position in this context. What appraoches can be presented to reach to an acceptable competition level in this industry. The first step is to achieve the approach mentioned in response of question above. Then, using the opportunity from removing the sanctions and regarding interest by leading shipbuilding and ship repair companies, selection of reliable company or foreign companies with willingness to industrial investment by considering priority of the national long term benefits, arrival of new technology and experts to the company should come to realize, sought to increase productivity and competitiveness. The next step which includes centralizing the workshops and required service providers at domestic and foreign private sector, providing strong logistic facilities to facilitate reaching the requirements and parts to repair work shops from various regions of the world, using development and research sector together with making relationship with scientific centers of country, making marketing and advertising and increasing quality and reducing repair cost and time have changed this major industry to put in the trajectory of international competition. It should be noted that re-experiencing is mistake. It requires selecting a shortcut and using reliable trade and industrial partners to use their experiences, technology and facilities to proliferate our progress. Yet, attracting partners' trust and ensuring them to gain profit of both sides against obtained income will ensure stable cooperation between them. If it is supposed to start anything from the beginning, we will not reach to the competitors who have taken speed at the middle of way. It should stick on mind that today's world due to progress in science and technology, closed communications, sharing mutual information which has connected the nations worldwide has developed a global integrated industrial hub in which all nations like gears of a complex machine in science, technology and industry in line with progress are in interaction with each other.

\section{Conclusions}

Role of geographical position of country by having water border extensiveness in the north and south to $2440 \mathrm{~km}$ area located in ship transport region from east to west of Strait of Hormuz that lacks Tropical Revolving Storms indicates high potential of country to attract demand for ship repair and maintenance. On the other hand, the weaknesses of this industry are as follows: 
- Repair costs are higher;

- Quality of repairs and services are relatively at lower level;

- Duration of periodic repair (dry dock repair) and even a voyage repair which is the most important factor at shipping companies is higher;

- Shortage of specialized human resources related to repairs;

- Poor management performance at this strategic industry is evident which can be due to lack of management instruments or other factors;

- Decentralization of facilities, providers of equipment, spare parts and associated industries at repair dry dock area and weakness or lack of technical competency of some contractors;

- Lack of foreign agencies and modern technologies, lack of participation by leading foreign repair companies, shortage of specialized workshops and requirements used in dry docks;

- Government's low attention as well as negative effect of bureaucracy governing it at this industry;

- Negative effect of currency rate fluctuation, lack of transparency and stability in customs rules and regulations, and cumbersome rules associated to supply of required parts and requirements as well as long importing process of parts and equipment;

- Negative influence of relatively low economic progress and shipping marketing on success at this industry and abundant effects from international sanctions and less welcome to countries in economic activities due to concern on going under sanction;

- Weakness in suitable strategy formulation for arrival by industrial investors at private sector of this industry to centralize effective facilities at this sector such as leading countries at this area;

- Weakness at use of logistic systems services in fast supply of required repair parts and equipment despite appropriateness of suitable geographical position of country;

- Failure of dry docks in attracting the required domestic and foreign experts at this industry as the result of low wage and lack of welfare facilities at this area.

\section{Suggestions}

- Quality of repairs in Singapore and fast and cheap repairs in china can be a model to our country. Due to acceptable factors such as price and logical repair duration which are the most important factors to attract customers, we witness the most ship repairs in a country like china. Cheap repair cost in that country is due to cheap manpower and available technology. The required experts with high productivity, discipline and speed at affairs assigned to them with the least waste of time, dominance of strong management at the centers of shipyards and dry docks at that country and as a result significant order in making affairs, ease of access to the required parts, equipment and instruments and having the advanced technology together with modified 
rules have ensured success in that country. Thus, having the model ongoing China in repair dry docks and shipbuildings seems a vital affair.

- Study and analysis on experts' views at the organizations affiliated to maritime industries in country such as customs department, national development fund, cabinet Experts and consultants to submit proposals to modify rules and regulations in line with national benefits.

- Develop a Working Group "ship repairs" by participation of agents from Legislature, executive and judicial to modify all associate cumbersome rules.

\section{References}

[1] http://shooshmall.com/blog

[2] Omaraei, B. (2015) A Trajectory in Maritime Transport Developments. 2nd Edition, Asrar Danesh Publication.

[3] Ozgur, U. (2008) The Interaction between the Ship Repair, Ship Conversion, Rison and Ship Building Industries. http://www.oecd.org/sti/ind/42033278

[4] Mayahi, J. (2008) Status of Ship Repair in Iran and Neighbor Countries. Payame Darya Journal. http://vista.ir/article/332228

[5] Roshandeli, M. (2009) Pathology of Maritime Industries in Country. Transport Industry Journal, 182713.A.

[6] Vaferi, M. (2010) Sanction on Maritime Transport of Country and Leading Approaches. Tine News Site.

[7] Tine News Site Website, 2014. http://www.tinn.ir/fa/doc/report/19147

[8] https://fa.wikipedia.org/wiki

[9] http://www.aftabir.com/articles

[10] Boris Butman (2014) Fundamentals of Ship Maintenance and Repair for Future Marine Engineers.pdf. http://iamu-edu.org/wp-content/uploads/2014/07 